\title{
Correction to: Short-term progression of cardiometabolic risk factors in relation to age at type 2 diabetes diagnosis: a longitudinal observational study of 100,606 individuals from the Swedish National Diabetes Register
}

\author{
Andri O. Steinarsson ${ }^{1} \cdot$ Araz Rawshani $^{2} \cdot$ Soffia Gudbjörnsdottir ${ }^{2,3} \cdot$ Stefan Franzén $^{3} \cdot$ Ann-Marie Svensson $^{3}$. \\ Naveed Sattar ${ }^{4}$
}

Published online: 2 September 2019

(C) Springer-Verlag GmbH Germany, part of Springer Nature 2019

Correction to: Diabetologia

https://doi.org/10.1007/s00125-017-4532-8

Unfortunately, the symbols in Fig. 1 were incorrectly described in the legend. The corrected figure is given here.

The online version of the original article can be found at https://doi.org/ $10.1007 / \mathrm{s} 00125-017-4532-8$

Soffia Gudbjörnsdottir

soffia.gudbjornsdottir@medic.gu

$\triangle$ Naveed Sattar

naveed.sattar@glasgow.ac.uk

1 School of Health Science, Faculty of Medicine, University of Iceland, Reykjavík, Iceland

2 Department of Molecular and Clinical Medicine, Institute of Medicine, University of Gothenburg, Gothenburg, Sweden

3 The Swedish National Diabetes Register, Västra Götalandsregionen, Gothenburg, Sweden

4 BHF Glasgow Cardiovascular Research Centre, Institute of Cardiovascular and Medical Sciences, University of Glasgow, 126 University Place, Glasgow G12 8TA, UK 
Fig. 1 Yearly averages (95\% CI) stratified by age group for (a) BMI, (b) $\mathrm{HbA}_{1 \mathrm{c}}$, (c) triacylglycerol, (d) HDLcholesterol and (e) LDLcholesterol. Circles, 18-44 years old; squares, 45-59 years old; diamonds, $60-74$ years old; triangles, $\geq 75$ years old. All analyses, $p<0.05$ where $95 \% \mathrm{CI}$ do not overlap a

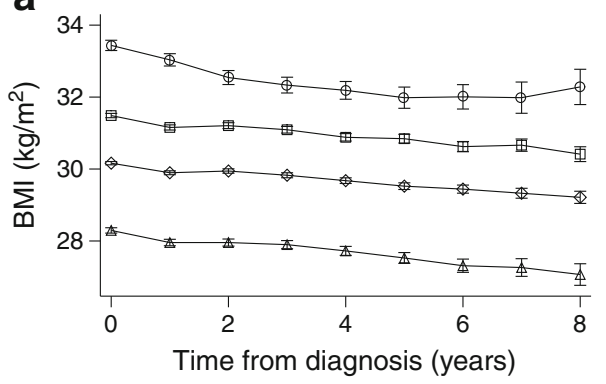

b

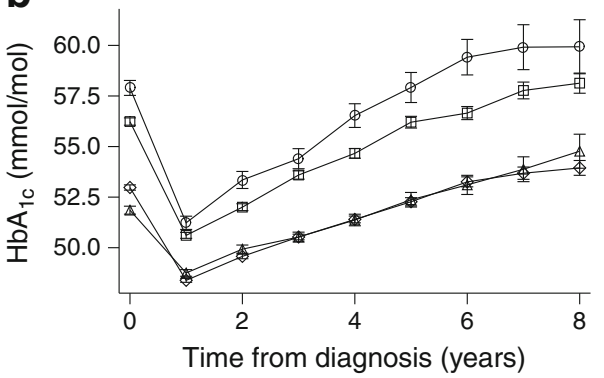

C

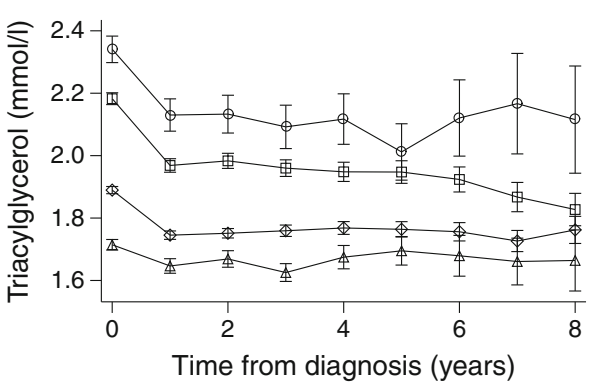

d

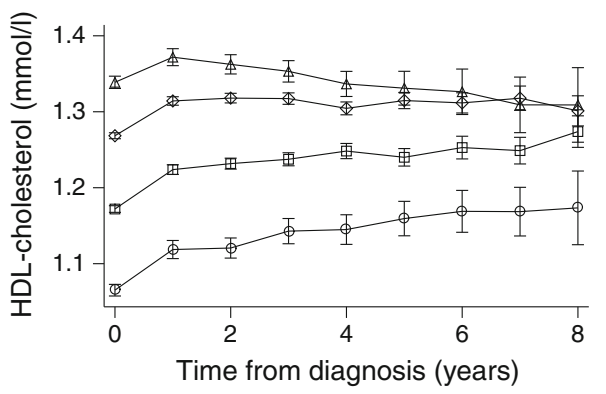

e

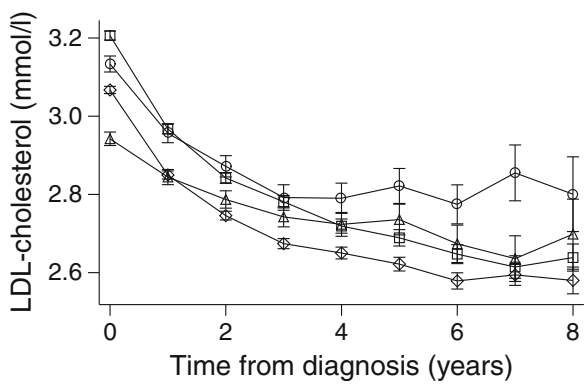

